\title{
Highly-dispersed nickel nanoparticles decorated titanium dioxide nanotube array for enhanced solar light absorption
}

\author{
Jian Chen ${ }^{\mathrm{a}}$, Yingke Zhou ${ }^{\mathrm{a},{ }^{*}}$, Ruizhi Li ${ }^{\mathrm{a}}$, Xi Wang ${ }^{\mathrm{a}}$, George Z. Chen ${ }^{\mathrm{a}, \mathrm{b},{ }^{*}}$

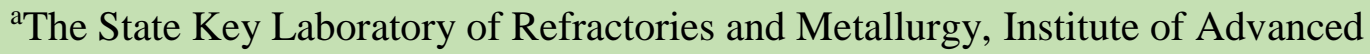 \\ Materials and Nanotechnology, College of Materials and Metallurgy, Wuhan \\ University of Science and Technology, Wuhan 430081, P. R. China. \\ E-mail: zhouyk888@hotmail.com.
}

${ }^{\mathrm{b}}$ Energy Engineering Research Group, Faculty of Science and Engineering, University of Nottingham Ningbo China, Ningbo 316100, P. R. China.

E-mail: george.chen@nottingham.ac.uk. 


\begin{abstract}
Honeycomb titanium dioxide nanotube array $\left(\mathrm{TiO}_{2}-\mathrm{NTA}\right)$ decorated by highlydispersed nickel nanoparticles (Ni-NPs) has been grown under control on Ti foil by anodization and subsequent electrodeposition. The pore diameter and length of $\mathrm{TiO}_{2}-$ NTA, and the size and quantity of Ni-NPs can be controlled via modulating the variables of the electrochemical processes. It has been found that the pretreatment of $\mathrm{TiO}_{2}$-NTA in the $\mathrm{Cu}\left(\mathrm{NO}_{3}\right)_{2}$ solution and further annealing at $450{ }^{\circ} \mathrm{C}$ in air could greatly improve the dispersion of the electrodeposited Ni-NPs. Absorption of the light in the solar spectrum from 300 to 2500 nm by the Ni-NPs@ $\mathrm{TiO}_{2}-\mathrm{NTA}$ is as high as $96.83 \%$, thanks to the co-effect of the light-trapping of $\mathrm{TiO}_{2}-\mathrm{NTA}$ and the plasmonic resonance of Ni-NPs. In the water heating experiment performed under an illuminating solar power density of $\sim 1 \mathrm{kWm}^{-2}$ (AM 1.5), the ultimate temperature over $66{ }^{\circ} \mathrm{C}$ and an overall efficiency of $78.9 \%$ within 30 min were obtained, promising for applications in photothermal conversion and solar energy harvest.
\end{abstract}

Keywords: titanium dioxide nanotube array; nickel nanoparticles; plasmonic resonance; light absorption; photothermal conversion 


\section{Introduction}

Photo-thermal conversion, the direct way of solar utilization, is one of the key methods to harvest solar energy and has been widely studied in, for example, water steam generation [1-5], desalination [6-8], solar thermal power generation [9, 10], solar thermoelectric conversion [11, 12], and solar fuel production [13]. A highly efficient absorber is the crucial part of a solar collection system, which absorbs solar energy, converts it directly to thermal energy which is then absorbed by a heat transfer fluid. As of now, there are three types of mainstream photothermal conversion materials that have been proposed and studied, including the carbon-based materials, metallic plasmonic materials and semiconducting materials $[14,15,16]$.

Up to now, various metal nanoparticles (e.g., Au-NPs [15], Ag-NPs [17], Al-NPs $[6,18]$ and In-NPs [7]) have been found excellent for light absorption and photothermal conversion based on the surface plasmonic resonance, a collective oscillation of free electrons in the metal stimulated by photons with the matching frequency [19]. Nevertheless, there are some barriers to large-scale applications. For instance, Au and $\mathrm{Ag}$ are noble metals, leading to a high cost, whilst Al-NPs and In-NPs with relatively chemical activity are usually prepared by a complex process, including vacuum deposition. In Ni-NPs, the transitions of sp-electrons and partially filled d-bands $\left(3 d^{8}\right)$ contribute to enhanced absorption in a broader spectral region [20-22], which is desired for harvesting solar energy [23, 24]. Although their light absorption capability is weaker than noble metal nanoparticles, Ni-NPs are a promising alternative for light absorption due to their low-cost as well as feasible and facile synthesis by various methods, 
including chemical reduction and electrodeposition $[25,26]$.

$\mathrm{TiO}_{2}$, a widely studied semiconductor with a wide band gap of $\sim 3.2 \mathrm{eV}$, only responds to the ultraviolet ( $7 \%$ of total spectrum) and is usually served as the matrix or support in absorbing materials owing to the good stability, such as $\mathrm{C}-\mathrm{TiO}_{2}$ [27], CNT$\mathrm{TiO}_{2}[28]$ and $\mathrm{Au}-\mathrm{TiO}_{2}$ [29], where various rough or porous surface structures are designed to improve absorption by suppressing the surface reflection. Recently, micro/nano-porous structures with strong light absorption have been designed for solar harvesting due to the improved light-trapping effect of the geometrical interspace, where light goes through multiple reflections and scattering internally, and is absorbed gradually [30-32]. For example, an ultra-low reflectance of $0.045 \%$ was achieved on vertical carbon nanotube arrays. Besides, a series of raised micro-nano structures have been in situ fabricated by laser writing on $\mathrm{Si}$ [33], copper [34], titanium and tungsten surfaces [35], which all exhibit reflectance below 2.5\%. For instance, a recent study demonstrated that the wedge-shaped $\mathrm{TiO}_{2}$ array could absorb light in the whole solar spectrum [36].

Herein, we report the fabrication of the honeycomb-shaped $\mathrm{TiO}_{2}-\mathrm{NTA}$ decorated with Ni-NPs on Ti foil by anodization and subsequent electrodeposition. The porous $\mathrm{TiO}_{2}$-NTA not only provide the structure for light-trapping but also function as the support for 3-D distributed plasmonic Ni-NPs. The fabrication process is illustrated in Fig.1. Interestingly, Ni-NPs have been found to uniformly deposit on the $\mathrm{TiO}_{2}-\mathrm{NTA}$, and the optimized Ni-NPs @ $\mathrm{TiO}_{2}$-NTA hybrid exhibits a strong absorption in the solar spectrum of $0.3 \sim 2.5 \mu \mathrm{m}$, confirming the potential application of this unique hybrid for 
harvesting solar energy.

\section{Experimental Section}

\subsection{Preparation of $\mathrm{TiO}_{2}-\mathrm{NTA}$}

Ti sheets $\left(99.5 \%\right.$ purity) were cut into desired sizes (e.g. $\left.50 \times 33 \times 0.2 \mathrm{~mm}^{3}\right)$, polished from coarse to fine on sand papers, ultrasonically cleaned in ethanol and dried in air. Adhesive tapes were to used cover the back of the Ti sheet so that only one side of the sheet with an area of $10 \mathrm{~cm}^{2}$ was exposed to the electrolyte. Highly uniform and ordered amorphous $\mathrm{TiO}_{2}$-NTA (a-TiO 2 -NTA) were fabricated by a two-step anodization process [37]. All the anodization experiments were carried out at $25{ }^{\circ} \mathrm{C}$ in a conventional two-electrode cell with graphite as the cathode. The first-step was performed at $20,40,60,80 \mathrm{~V}$ for $0.5 \mathrm{hr}$ in the ethylene glycol electrolyte containing $0.7 \mathrm{wt} \% \mathrm{NH}_{4} \mathrm{~F}, 6$ vol\% $\mathrm{H}_{2} \mathrm{O}$ and 4 vol $\% \mathrm{H}_{3} \mathrm{PO}_{4}$. The first-anodized a-TiO 2 -NTA were washed in deionized water and the anodized film was taken off using an adhesive tape to expose the pre-patterned Ti substrate. The second-step anodization was performed in the identical electrolyte for 10 70 min, and the voltage was usually $20 \mathrm{~V}$ higher than the corresponding first-step. The samples were then washed in ethanol to remove the residual electrolyte and the adhesive tape was removed from the back of the anodized $\mathrm{Ti}$ sheet. Subsequently, the anodized $\mathrm{Ti}$ sheets were soaked into a $0.05 \mathrm{M}$ $\mathrm{Cu}\left(\mathrm{NO}_{3}\right)_{2} \cdot 3 \mathrm{H}_{2} \mathrm{O}$ ethanol solution for $6 \mathrm{hr}$ and annealed in air at $450{ }^{\circ} \mathrm{C}$ for $3 \mathrm{hr}$.

\subsection{Preparation of $\mathrm{Ni}-\mathrm{NPs} @ \mathrm{TiO}_{2}-\mathrm{NTA}$}

The Ni-NPs were deposited on the wall and surface of the $\mathrm{TiO}_{2}$-NTA by electrodeposition under a constant current in a two-electrode cell containing $0.3 \mathrm{M}$ 
$\mathrm{NiSO}_{4} \cdot 7 \mathrm{H}_{2} \mathrm{O}, 0.3 \mathrm{M} \mathrm{H}_{3} \mathrm{BO}_{3}$ and $0.1 \mathrm{~g} \mathrm{~L}^{-1}$ lauryl sodium sulfate. In this cell, the cathode was the annealed $\mathrm{Ti}$ sheet, and the anode was graphite. The electrodeposition was carried out at $35{ }^{\circ} \mathrm{C}$ under a high current density of $30 \mathrm{~mA} \mathrm{~cm}^{-1}$ for $0 \sim 100 \mathrm{~s}$. Finally, the obtained black samples were washed in water, and dried at $80{ }^{\circ} \mathrm{C}$ in air.

\subsection{Characterization of materials}

The morphology of Ni-NPs@ $\mathrm{TiO}_{2}$-NTA on the Ti substrate was characterized with a scanning electron microscope (SEM, PHILPS XL30TMP). The phase compositions of the samples were recorded by an X-ray diffractometer (XRD, Xpert Pro MPD). The superficial elementary composition and chemical state were characterized by the X-ray photoelectron spectroscopy (XPS, ESCALAB 250Xi). Optical properties (reflectance and absorptance) and band gap were measured by a UV-Vis and NIR spectrophotometer (Shimadzu 3600 UV/Vis and Shimadzu 2600 UV/Vis) incorporated

with an integrating sphere. The overall thermal efficiencies of samples were investigated using an in-house designed water heating cell under the radiation (AM 1.5) of a solar simulator (LSP-X500A). The simulated sunlight irradiated on the NiNPs@ $\mathrm{TiO}_{2}$-NTA side of the Ti sheet whose back side formed a part of the wall of the water heating cell containing $8.5 \mathrm{~mL}$ water.

\section{Results and discussion}

\subsection{Morphologies and structures}

The digital photographs shown in Fig. 2 were taken from the surfaces of the Ti sheet at the end of each step of polishing and cleaning (Fig. 2a), removing the first-anodized film (Fig. 2b), soaking and annealing (Fig. 2c), and depositing Ni-NPs (Fig. 2d). As 
shown in Fig. 2b-2d, the gradual darkening of the sample indicates that light absorption would be enhanced seriatim. Typical SEM images of various samples are displayed in Fig. 2e-2h. The pre-patterned Ti substrate after using adhesive tape to remove the firstanodized film was shown in Fig. 2e. The uniform $\mathrm{TiO}_{2}$ NTA samples with an assemble of unit cells with diameter of 150 200 nm were constructed after the two-step anodization (Fig. 2f). After annealing and constant current depositing, the sparse NiNPs with an average diameter of $\sim 65 \mathrm{~nm}$ were deposited on the inner wall of each $\mathrm{TiO}_{2-}$ NTA (Fig. 2g). However, when the $\mathrm{TiO}_{2}$ NTAs were soaked in the dilute $\mathrm{Cu}\left(\mathrm{NO}_{3}\right)_{2}$ solution before annealing, the densely packed Ni-NPs with clear contour profiles and decreased average diameter of $\sim 40 \mathrm{~nm}$ were uniformly deposited on both the top and wall of each $\mathrm{TiO}_{2}$-NTA (Fig. 2h).

Furthermore, compared to the reported works [38, 39], the as-prepared Ni-NPs are smaller in size and highly distributed on each $\mathrm{TiO}_{2}-\mathrm{NTA}$, which indicates that the soaking treatment played a key role in the formation of Ni-NPs. Moreover, we observed that when electrodeposition was carried out directly of the annealed Ti sheet without the $\mathrm{TiO}_{2}$-NTA coating, the deposited $\mathrm{Ni}$ formed a continuous, smooth, and dense silvery coating. This change is markedly different from the granular and black Ni-NPs on the $\mathrm{TiO}_{2}$-NTA. The cause may be that the higher resistance of the $\mathrm{TiO}_{2}-\mathrm{NTA}$ reduced the growth rate and the final size of $\mathrm{Ni}-\mathrm{NPs}$ [40], and the porous $\mathrm{TiO}_{2}-\mathrm{NTA}$ offered more 3-D deposition sites for Ni-NPs to hinder the reunion of Ni-NPs [41].

The morphological features of Ni-NPs@ $\mathrm{TiO}_{2}-\mathrm{NTA}$, such as pore size, thickness (or the length of the nanotubes) and particle size and amount of Ni-NPs, are the 
determinants for light absorption, which were investigated by finely controlling the electrochemical parameters. The diagram shown in Fig. 3a manifests that the pore size of $\mathrm{TiO}_{2}$-NTA increases with the anodization voltage due to the enhanced electric field [42]. As shown in Fig. 3b, the thickness of $\mathrm{TiO}_{2}-\mathrm{NTA}$ also increases with the anodization time, but the growth speed is slowing down. In Fig. 3c-3h, the average particle sizes of Ni-NPs with different deposition times are about 20, 30, 40, 60, 100 and $150 \mathrm{~nm}$, respectively. It is obvious that the particle size and amount of Ni-NPs increase continuously as deposition time increases. As a result, the remaining pore size gradually shrinks and disappears eventually.

The XRD patterns of as-prepared and heat treated Ni-NPs@ $\mathrm{TiO}_{2}-\mathrm{NTAs}$ are shown in Fig. 4a. The main ingredients of the sample dried at $80{ }^{\circ} \mathrm{C}$ are confirmed to be anatase- $\mathrm{TiO}_{2}$ by the diffraction peaks at $25.3^{\circ}, 37.8^{\circ}, 48.0^{\circ}, 53.9^{\circ}$ and $55.0^{\circ}(\mathrm{JCPDF}$ No. 21-1272), metallic Ni at $44.5^{\circ}$ and $76.4^{\circ}$ (JCPDF No. 04-8050). The diffraction peaks at $35.1^{\circ}, 38.4^{\circ}, 40.2^{\circ}, 53.0^{\circ}, 62.9^{\circ}$ and $70.6^{\circ}$ belong to the substrate $\mathrm{Ti}(\mathrm{JCPDF}$ No. 44-1294). There were no visible diffraction peaks of $\mathrm{NiO}$ in the XRD patterns if the sample was heated at temperatures lower than $250{ }^{\circ} \mathrm{C}$, indicating that the metallic $\mathrm{Ni}$ is stable in air below $250{ }^{\circ} \mathrm{C}$. When the temperature rose to $300{ }^{\circ} \mathrm{C}$ and $350{ }^{\circ} \mathrm{C}$, the apparent diffraction peak at $43.2^{\circ}$ for $\mathrm{NiO}$ (JCPDF No. 47-1049), as well as the enlarged diameter Ni-NPs shown in Fig.4b indicate that the Ni-NPs were oxidized and transformed to $\mathrm{NiO}$. In later experiments, the Ni-NPs@ $\mathrm{TiO}_{2}-\mathrm{NTA}$ were heated at $500{ }^{\circ} \mathrm{C}$ for $5 \mathrm{~h}$ in a reducing atmosphere containing 5\% hydrogen. As shown in Fig.4c, in the reducing atmosphere, the Ni-NPs deposited on side wall of $\mathrm{TiO}_{2}-\mathrm{NTA}$ grew up 
due to the combination of smaller particles at high temperatures, whilst the Ni-NPs deposited on top of $\mathrm{TiO}_{2}$-NTA were still spherical.

\subsection{Light absorption}

The light absorption abilities of the Ni-NPs@ $\mathrm{TiO}_{2}-\mathrm{NTA}$ samples were measured via spectrophotometers with an integrating sphere and evaluated by absorptance and reflectance. The weighted solar absorptance $(\alpha)$ was calculated according to the measured reflection spectrum and standard solar radiation spectrum by the following equations [43]:

$$
\alpha=\frac{\int_{0.3}^{2.5 \mu \mathrm{m}}(1-R(\lambda)) I_{\text {sol }}(\lambda) d \lambda}{\int_{0.3 \mu \mathrm{m}}^{2.5 \mu \mathrm{m}} I_{\text {sol }}(\lambda) d \lambda}
$$

where $\lambda$ is the wavelength, $R(\lambda)$ is the reflectance of per unit wavelength for the fabricated samples. $I_{\text {sol }}(\lambda)$ is the solar radiation intensity of per unit wavelength, accroding to the ISO standard 9845-1(1992) of AM 1.5. The band gap (or energy gap) of the different $\mathrm{TiO}_{2}$ samples was calculated by the Kubelka-Munk equation of $F(R)=(1-R)^{2} /(2 R)$, where $R$ is the reflectance relative to $\mathrm{BaSO}_{4}[44]$.

As shown in Fig. 5a, the polished Ti sheet showed the highest reflectance because of the well-polished surface and intrinsic low absorption of metallic Ti. Compared to the compact $\mathrm{TiO}_{2}$ film on annealed $\mathrm{Ti}$, the absorptance of $\mathrm{TiO}_{2}-\mathrm{NTA}$ further increased as the porous surface captured more light. The lowest reflectance was observed on the Ni-NPs@ $\mathrm{TiO}_{2}$-NTA sample due to the intensive additional absorption of Ni-NPs based on plasma resonance, which is a well-known effect of metal nanoparticles. Although it has been reported that $\mathrm{CuO}$ nanoparticles also exhibit the absorption, scattering and plasmon effect in the solar spectrum [45], the low content ( $\sim .56$ at $\% \mathrm{Cu}$ from EDS but 
invisible in SEM images) and the cover of Ni-NPs may lead to little absorption via $\mathrm{CuO}$ itself. As shown in Fig. 5b, the absorption cutoff wavelength $\left(\lambda_{1}\right.$ and $\left.\lambda_{2}\right)$ of the $\mathrm{TiO}_{2-}$ NTA without and with soaking is respectively $\sim 390 \mathrm{~nm}$ and $415 \mathrm{~nm}$, and the $\mathrm{TiO}_{2}$-NTA with soaking exhibits stronger absorption in the visible light region, but weaker in the ultraviolet region. The possible reason is that the $\mathrm{CuO}$ with a narrow band gap of $\sim 1.7$ $\mathrm{eV}$ has a strong absorption capacity in the visible region and may decrease the absorption of the $\mathrm{TiO}_{2}$-NTA in the ultraviolet region due to the shielding effect. The Kubelka-Munk plots in the insert of Fig. 5b demonstrate the band gaps of 3.11 and 2.90 $\mathrm{eV}$ of the unsoaked and soaked samples, and the reduced bandgap of the latter may be originated from the $\mathrm{Cu}^{2+}$ doping of the substrate [46]. Compared to the unsoaked sample, the absorption of the Ni-deposited $\mathrm{TiO}_{2}$-NTA with soaking is increased by $\sim 5 \%$ (Fig. 5c), and the amount of the Ni-NPs is increased and the size is decreased (Fig. $2 \mathrm{~g}$ and 2h), indicating that a small quantity of $\mathrm{CuO}$ resulted from the decomposion of the absorbed $\mathrm{Cu}\left(\mathrm{NO}_{3}\right)_{2}$ may enhance the absorption of $\mathrm{Ni}-\mathrm{NPs} @ \mathrm{TiO}_{2}-\mathrm{NTA}$ by modulating the nucleation and changing the morphology of the Ni-NPs [47]. Furthermore, the competitive growth of between different Ni-NPs may restrain themselves to grow larger within the microscopic space of the $\mathrm{TiO}_{2}$ nanotubes where electrolyte and $\mathrm{Ni}^{2+}$ supply was limited. As a result, the Ni-NPs with smaller size $(\sim 40 \mathrm{~nm})$ and well distributed on the $\mathrm{TiO}_{2}$-NTA, exhibited stronger light absorption in the band of $300 \sim 1200 \mathrm{~nm}$, but a lower absorption in the middle to far infrared regions, which can be ascribed to the sizedependent resonance theory that the most intense absorption region of plasmonic metal particles depends on their size and shape, and the absorption band red shifts with the 
increase of particle size and aspect ratio [48-51]. By the way, absorption region varies with the size of Ni-NPs, therefore the very many Ni-NPs with varying sizes could exhibit a broad light absorption region. Fig.5d shows the reflection spectra for the $\mathrm{Ni}$ NPs@ $\mathrm{TiO}_{2}$-NTA with different pore sizes. It can be seen that the absorption region and overall absorptance are approximately equal, indicating that the absorption for $\mathrm{Ni}$ NPs@ $\mathrm{TiO}_{2}$-NTA is not sensitive to the pore size. Although a larger $\mathrm{TiO}_{2}$ nanotube can accommodate more Ni-NPs and capture more light for a single nanotube, the whole surface area and amount of loaded Ni-NPs are inversely proportional to the diameter of the pore. Therefore, the Ni-NPs@ $@ \mathrm{TiO}_{2}-\mathrm{NTA}$ anodized at $60 \mathrm{~V}$ with the appropriate pore size of $\sim 145 \mathrm{~nm}$ showed the highest absorptance.

The influence of the Ni-NPs@ $\mathrm{TiO}_{2}$-NTA thickness on light absorption is demonstrated in Fig. 6a. Firstly, distinct fluctuations can be seen in the reflection spectra for Ni-NPs@ $\mathrm{TiO}_{2}-\mathrm{NTA}$ with thickness of 0.5 and $1.0 \mu \mathrm{m}$, which can be ascribed to the destructive and constructive interferences $[52,53]$. Also, the overall absorptance increases with the thickness due to more thorough absorption in the longer optical path. Specifically, as the coatings became thicker, more Ni-NPs were deposited on the inner walls and more reflection and scattering occurred in the tubes, contributing to higher absorptance. Although the absorptance of the $2.5 \mu \mathrm{m}$ thick coating was up to $97.24 \%$, the coating would crimp and detach from the Ti substrate easily, likely because growth in thick Ni-NPs@ $\mathrm{TiO}_{2}$-NTA was likely uneven, and hence cause localized stress development. Therefore, an optimal thickness of $2 \mu \mathrm{m}$ was set in the subsequent experiments. 
As shown in Fig. 6b, the reflection spectra are shown for a series of Ni-NPs@ $\mathrm{TiO}_{2}-$ NTA anodized at $60 \mathrm{~V}$ for $50 \mathrm{~min}$ followed by electrodeposition at various times. With the extension of deposition time (less than $25 \mathrm{~s}$ ), the amount and size of Ni-NPs increased gradually, due to the adequate nucleation and growth of the particles. The whole band absorptance increased with the increase of the number of Ni-NPs. The NiNPs@ $\mathrm{TiO}_{2}$-NTA obtained from deposition for $25 \mathrm{~s}$ displayed the highest absorptance of visible light and a maximum whole spectrum absorptance of $96.83 \%$, which is comparative to that of the reported materials with similar porous structures, such as the Al-NPs@ $\mathrm{Al}_{2} \mathrm{O}_{3}-\mathrm{NTA}(\sim 96 \%), \mathrm{Au} @ \mathrm{Al}_{2} \mathrm{O}_{3}(91 \%)$ and the $\mathrm{Ni}$ particles pigmented anodized aluminum $(94-96 \%)$ [4, 29, 54]. However, when the deposition time was further prolonged (more than $25 \mathrm{~s}$ ), the deposited Ni-NPs grew big enough to fill the pores. The pore size gradually decreased with the continuous deposition of Ni particles, and more light was reflected off the surface, rather than enter the nanotubes, leading to the deterioration of absorptance especially for the visible light (the color of the sample converted to yellow and white).

The Ni-NPs@ $\mathrm{TiO}_{2}$-NTA samples were further thermally treated at different temperatures and atmospheres. As shown in Fig. 6c, the absorptance did not decline when the temperature was lower than $250{ }^{\circ} \mathrm{C}$, but significantly deteriorated at $300{ }^{\circ} \mathrm{C}$, indicating that the metallic Ni-NPs with high light absorption could remain stable at $250{ }^{\circ} \mathrm{C}$, but the nickel oxides formed at higher temperatures behaved poorly in light absorption. On the other hand, the substances such as black nickel compounds of 
$\mathrm{NiOOH}$ and $\mathrm{Ni}_{2} \mathrm{O}_{3}$ may both exist in the Ni-NPs@ $\mathrm{TiO}_{2}-\mathrm{NTA}$ and contribute to light absorption. In later experiments, the Ni-NPs@ $\mathrm{TiO}_{2}-\mathrm{NTA}$ were heated at $500{ }^{\circ} \mathrm{C}$ in the reducing atmosphere containing 5\% hydrogen. Consequently, the reflectance as shown in Fig. 6d attenuated slightly in the visible region and a little enhancement in the infrared region, probably due to the growth, fusion and aggregation of Ni-NPs at 500 ${ }^{\circ} \mathrm{C}$. In summary, the high and deteriorated absorptances of $\mathrm{Ni}-\mathrm{NPs} @ \mathrm{TiO}_{2}-\mathrm{NTA}$ without and with thermal oxidation indicate that the metallic Ni-NPs with sufficient number of free electrons are crucial to the high absorptance.

\subsection{Photothermal conversion}

To directly observe the photothermal conversion properties of Ni-NPs@ $\mathrm{TiO}_{2}-\mathrm{NTA}$, water heating experiments (shown as Fig.7a and 7b) were performed. The samples were combined into plastic boxes with a volume of $3 \times 3 \times 1 \mathrm{~cm}^{3}$, in which $8.5 \mathrm{~mL}$ water with an initial temperature of $20.5 \pm 0.2^{\circ} \mathrm{C}$ was filled up and a thermometer was inserted to monitor the temperature. In addition, the plastic boxes were thermally insulated by closed-cell foam to reduce heat loss. The light was provided by a solar simulator with standard radiation intensity of AM 1.5. The sample was irradiated vertically for $60 \mathrm{~min}$, and the temperature variation was recorded every minute. As the thickness of NiNPs@ $\mathrm{TiO}_{2}-\mathrm{NTA}$ is far less than that of the Ti sheet $(\sim 200 \mu \mathrm{m})$, all samples are approximately identical in thickness and thermal conductivity. Therefore, the heat generated at the top surface conducts to the Ti substrate and then to the water whose temperature can be detected to evaluate the average thermal efficiency (ATE). The ATE can be calculated by equation (2) [55], 


$$
\eta=\frac{C \times m \times \Delta T}{I \times S \times t}
$$

where $C$ is the specific heat capacity of water which is approximately $4200 \mathrm{~J} \mathrm{~kg}^{-}$ ${ }^{1} \mathrm{~K}^{-1}, m$ the mass of water (ca. $8.5 \mathrm{~g}$ ), $\Delta T$ the temperature rise, $I$ the power density of the light source $\left(1 \mathrm{~kW} \mathrm{~m}^{-2}\right), S$ the irradiated area of the sample $\left(10 \mathrm{~cm}^{2}\right)$, and $t$ the time for irradiation. Consider that the heating rates of all the samples decreased gradually and reached at the equilibrium temperature within $57 \mathrm{~min}$, we calculated the overall PTEC of irradiation for $30 \mathrm{~min}$ and $57 \mathrm{~min}$, respectively. Obviously, the ATE for 30 min was higher than that for $57 \mathrm{~min}$ because the thermal loss, particularly infrared radiation and conduction, also increased with the temperature.

In Fig. 7c and 7e, it is obvious that the polished $\mathrm{Ti}$ sheet demonstrated the lowest heating rate and ATE due to its high reflectance $(>40 \%)$. As the thickness of the NiNPs@ $\mathrm{TiO}_{2}-\mathrm{NTA}$ increased, the heating rate and the equilibrium temperature also increased, and the $2 \mu \mathrm{m}$ thick Ni-NPs@ $\mathrm{TiO}_{2}$-NTA showed the fastest heating and the highest equilibrium temperature $\left(66.5^{\circ} \mathrm{C}\right)$ and ATE $(78.9 \%$ for $30 \mathrm{~min}$ and $48.0 \%$ for $57 \mathrm{~min}$ ), which can be positively correlated with the absorptance. In Fig. 7d and 7f, the heating rate, the equilibrium temperature and the overall PTCE are also positively correlated with the absorptance, and the $2 \mu \mathrm{m}$ thick Ni-NPs@ $\mathrm{TiO}_{2}-\mathrm{NTA}$ obtained by $25 \mathrm{~s}$ deposition showed the highest ATE.

\section{Conclusions}

The Ni-NPs@ $@ \mathrm{TiO}_{2}-\mathrm{NTA}$ have been synthesized on the Ti substrate by anodization and electrodeposition. A pretreatment of the $\mathrm{TiO}_{2}-\mathrm{NTA}$ in the ethanol solution of $\mathrm{Cu}\left(\mathrm{NO}_{3}\right)_{2}$ can significantly downsize the Ni-NPs and enhance light absorption by about 
5\%. The absorptance increases with the thickness of the Ni-NPs@ $\mathrm{TiO}_{2}-\mathrm{NTA}$, but is not sensitive to the pore size. Moreover, the size and amount of Ni-NPs have a significant influence on light absorption. Thanks to the light-trapping ability of the porous $\mathrm{TiO}_{2-}$ NTA and the surface plasmon resonance of Ni-NPs, a high absorptance of $96.83 \%$ in the solar spectrum from 300 to $2500 \mathrm{~nm}$ has been achieved. In the water heating experiment, the highest temperature over $66{ }^{\circ} \mathrm{C}$ and an overall efficiency of $78.9 \%$ within 30 min irradiation have been obtained, implying the potential applications of the Ni-NPs@TiO 2 -NTA in light-to-heat conversion and solar energy harvest.

\section{Acknowledgements}

This work was supported by the National Natural Science Foundation of China (No. 51372178) and the Natural Science Foundation of Hubei Province of China (No. 2013CFA021, 2018CFA022). 


\section{Reference}

[1] G. Ni, G. Li, S.V. Boriskina, H. Li, W. Yang, T. Zhang, G. Chen, Steam generation under one sun enabled by a floating structure with thermal concentration, Nat. Energy 1 (2016) 16126.

[2] K. Bae, G. Kang, S.K. Cho, W. Park, K. Kim, W.J. Padilla, Flexible thin-film black gold membranes with ultrabroadband plasmonic nanofocusing for efficient solar vapour generation, Nature Commu. 6 (2015) 10103.

[3] H.L. Ren, M. Tang, B.L. Guan, K.X. Wang, J.W. Yang, F.F. Wang, M.Z. Wang, J.Y. Shan, Z.L. Chen, D. Wei, H.L. Peng and Z.F. Liu, Hierarchical Graphene Foam for Efficient Omnidirectional Solar-Thermal Energy Conversion, Adv. Mater. 29 (2017) 1702590.

[4] L. Zhou, Y.L. Tan, D.X. Ji, B. Zhu, P. Zhang, J. Xu, Q.Q. Gan, Z.F. Yu and J. Zhu, Self-assembly of highly efficient, broadband plasmonic absorbers for solar steam generation, Sci. Adv. 2 (2016) 1501227.

[5] C.J. Chen, Y.J. Li, J.W. Song, Z. Yang, Y.D. Kuang, E. Hitz, C. Jia, A. Gong, F. Jiang, J.Y. Zhu, B. Yang, J. Xie and L.B. Hu, Highly Flexible and Efficient Solar Steam Generation Device, Adv. Mater. 29 (2017) 1701756.

[6] L. Zhou, Y. Tan, J. Wang, W. Xu, Y. Yuan, W. Cai, S. Zhu, J. Zhu, 3D self-assembly of aluminium nanoparticles for plasmon-enhanced solar desalination, Nat. Photo. 10 (2016) 393-398.

[7] L.L. Zhang, J. Xing, X.L. Wen, J.W. Chai, S.J. Wang, Q.H. Xiong, Plasmonic Heating from Indium Nanoparticles on a Floating Microporous Membrane for 
Enhanced Solar Seawater Desalination, Nanoscale 9 (2017) 12843-12849.

[8] M.Y. Shang, N. Li, S.D. Zhang, T.T. Zhao, C. Zhang, C. Liu, H.F. Li, Z.Y. Wang, Full-Spectrum Solar-to-Heat Conversion Membrane with Interfacial Plasmonic Heating Ability for High-Efficiency Desalination of Seawater, ACS Appl. Energy Mater. 1 (2017) 56-61.

[9] J.Y. Moon, D.L. Lu, B.V. Saders, T.K. Kim, S.D. Kong, S.H. Jin, R.K. Chen, Z.W. Liu, High performance multi-scaled nanostructured spectrally selective coating for concentrating solar power, Nano Energy 8 (2014) 238-246.

[10] Q.J. Mao, Recent developments in geometrical configurations of thermal energy storage for concentrating solar power plant, Renew. \& Sust. Energy Rev. 59 (2016) $320-327$.

[11] L.L. Baranowski, G.J. Snyder, E.S. Toberer, Concentrated solar thermoelectric generators, Energy \& Environ. Sci. 5 (2012) 9055-9067.

[12] A. Kosuga, Y. Yamamoto, M. Miyai, M. Matsuzawa, Y. Nishimura, S. Hidaka, K. Yamamoto, S. Tanaka, Y. Yamamoto, S. Tokonami, T. Iida, A high performance photothermal film with spherical shell-type metallic nanocomposites for solar thermoelectric conversion, Nanoscale 7 (2015) 7580-7584.

[13] X.G. Meng, T. Wang, L.Q. Liu, S.X. Ouyang, P. Li, H.L. Hu, T. Kako, H. Iwai, A. Tanaka, J.H. Ye, Photothermal conversion of $\mathrm{CO}_{2}$ into $\mathrm{CH}_{4}$ with $\mathrm{H}_{2}$ over Group VIII nanocatalysts: an alternative approach for solar fuel production, Angew. Chemi. 53 (2014) 11662-11666.

[14] J.L.Yang, Y.S. Pang, W.X. Huang, S.K. Shaw, J. Schiffbauer, M.A. Pillers, X. Mu, 
S.R. Luo, T. Zhang, Y.J. Huang, G.X. Li, S. Ptasinska, M. Lieberman, T.F. Luo, Functionalized Graphene Enables Highly Efficient Solar Thermal Steam Generation, ACS nano 11 (2017) 5510-5536.

[15] X.Z. Wang, Y.R. He, X. Liu, G. Cheng, J.Q. Zhu, Solar steam generation through bio-inspired interface heating of broadband-absorbing plasmonic membranes, Appl. Energy 195 (2017) 414-425.

[16] M.M. Ye, J. Jia, Z.J. Wu, C.X. Qian, R. Chen, P.G. O'Brien, W. Sun, Y.C. Dong, G.A. Ozin, Synthesis of Black $\mathrm{TiO}_{\mathrm{x}}$ Nanoparticles by $\mathrm{Mg}$ Reduction of $\mathrm{TiO}_{2}$ Nanocrystals and their Application for Solar Water Evaporation, Adv. Energy Mater. 7 (2017) 1601811.

[17] F. Wu, X.Y. Hu. J. Fan, E.Z. Liu, T. Sun, L.M. Kang, W.Q. Hou, C.J. Zhu, H.C. Liu, Photocatalytic Activity of $\mathrm{Ag} / \mathrm{TiO}_{2}$ Nanotube Arrays Enhanced by Surface Plasmon Resonance and Application in Hydrogen Evolution by Water Splitting, Plasmonics 8 (2013) 501-508.

[18] D.B. Zhang, X.F. Yang, X.K. Hong, Y.S. Liu, J.F. Feng, Aluminum nanoparticles enhanced light absorption in silicon solar cell by surface plasmon resonance, Opt. Quan. Electr. 47 (2014) 1421-1427.

[19] G. Dodekatos, S. Schunemann, H. Tuysuz, Surface Plasmon-Assisted Solar Energy Conversion, Top. Cur. Chem. 371 (2015) 215-252.

[20] S. Zhu, L.M. Wang, Optical and magnetic properties of Ni nanoparticles in rutile formed by Ni ion implantation, Appl. Phys. Lett. 88 (2006).

[21] V. Dalouji, Effect of deposition time on surface plasmon resonance and Maxwell- 
Garnett absorption in RF-magnetron sputtered carbon-nickel films, Mater. Sci. Poland 34 (2016) 337-343.

[22] X. Xiang, X.T. Zu, S. Zhu, L.M. Wang, Optical properties of metallic nanoparticles in Ni-ion-implanted $\alpha-\mathrm{Al}_{2} \mathrm{O}_{3}$ single crystals, Appl. Phys. Lett. 84 (2004) 52-54.

[23] M. Farooq, A.A. Green. M.G. Hutchins, High performance sputtered Ni : SiO2 composite solar absorber surfaces, Sol. Energy Mater. Sol. Cells 54 (1998) 67-73.

[24] F. Cao, D. Kraemer, T.Y. Sun, Y.C. Lan, G. Chen, Z.F. Ren, Enhanced Thermal Stability of W-Ni-Al ${ }_{2} \mathrm{O}_{3}$ Cermet-Based Spectrally Selective Solar Absorbers with Tungsten Infrared Reflectors, Adv. Energy Mater. 5 (2015) 1401042.

[25] L.H. Chou, W.C. Hung, M.T. Lee, On the Preparation of Nickel Nanoparticles by Chemical Reduction Method: X-ray Absorption Spectroscopy, Mater. Sci. 22 (2016) 305-308

[26] Y.H. Zhang, Y.N. Yang, P. Xiao, X.N. Zhang, L. Lu, L. Li, Preparation of Ni nanoparticle- $\mathrm{TiO}_{2}$ nanotube composite by pulse electrodeposition, Mater. Lett. 63 (2009) 2429-2431.

[27] B. Cheng, K.K. Wang, K.P. Wang, W. Jiang, B.J. Cong, C.L. Song, S.H. Jia, G.R. Han, Y. Liu, Porous carbon-titania nanocomposite films for spectrally solar selective absorbers, Sol. Energy Mater. Sol. Cells 133 (2015) 126-132.

[28] M.E. Rincón, J.D. Molina, M. Sánchez, C. Arancibia, E. García, Optical characterization of tandem absorber/reflector systems based on titanium oxidecarbon coatings, Sol. Energy Mater. Sol. Cells 91 (2007) 1421-1425.

[29] E.Z. Liu, J. Fan, X.Y. Hu, Y. Hu, H. Li, C.N. Tang, L. Sun, J. Wan, A facile strategy 
to fabricate plasmonic $\mathrm{Au} / \mathrm{TiO}_{2}$ nano-grass films with overlapping visible lightharvesting structures for $\mathrm{H}_{2}$ production from water, J. Mater. Sci. 50 (2014) 22982305.

[30] Y. Li, Z.Y. Fu, B.L. Su, Hierarchically Structured Porous Materials for Energy Conversion and Storage, Adv. Funct. Mater. 22 (2012) 4634-4667.

[31] S.K. Yang, N. Sun, B.B. Stogin, J. Wang, Y. Huang, T.S. Wong, Ultra-antireflective synthetic brochosomes, Nat. Commu. 8 (2017) 1285-1293.

[32] M. Suzuki, T. Yamamoto, Y. Katayama, S. Kuwata, T. Tanaka, Light Absorption by Metals with Porous Surface Layer Formed by Oxidization and Reduction Treatment, Mater. Trans. 53 (2012) 1556-1562.

[33] J. Yang, F.F. Luo, T.S. Kao, X. Li, G.W. Ho, J.H. Teng, X.G. Luo, M.H. Hong, Design and fabrication of broadband ultralow reflectivity black Si surfaces by laser micro/nanoprocessing, Light: Sci. Appl. 3 (2014) 185.

[34] P.X. Fan, H. Wu, M. L. Zhong, H. J. Zhang, B. F. Bai, G. F. Jin, Large scale cauliflower shaped hierarchical copper nanostructures for efficient photothermal conversion, Nanoscale 8 (2016) 14617-14624.

[35] P.X. Fan, B.F. Bai, M.L. Zhong, H.J. Zhang, J.Y. Long, J.P. Han, W.Q. Wang, G.F. Jin, General Strategy toward Dual-Scale-Controlled Metallic Micro-Nano Hybrid Structures with Ultralow Reflectance, ACS Nano 11 (2017) 7401-7408.

[36] C.L. Liu, W. Zhou, J.K. Song, H.J. Liu, J.H. Qu, L. Guo, G.F. Song, C.P. Huang, Nanostructure-induced colored $\mathrm{TiO}_{2}$ array photoelectrodes with full solar spectrum harvesting, J. Mater. Chem. A 5 (2017) 3145-3151. 
[37] X.M. Zhong, D.L. Yu, Y. Song, D.D. Li, H.P. Xiao, C.Y. Yang, L.F. Lu, W.H. Ma, X.F. Zhu, Fabrication of large diameter $\mathrm{TiO}_{2}$ nanotubes for improved photoelectrochemical performance, Mater. Res. Bull. 60 (2014) 348-352.

[38] H. Cheshideh, F. Nasirpouri, Cyclic voltammetry deposition of nickel nanoparticles on $\mathrm{TiO}_{2}$ nanotubes and their enhanced properties for electrooxidation of methanol, J. Electroanal. Chem. 797 (2017) 121-133.

[39] J.A. Díaz-Real, E.O. Ortega, M.P. Gurrola, J.L. Garcia, L.G. Arriaga, Lightharvesting $\mathrm{Ni} / \mathrm{TiO}_{2}$ nanotubes as photo-electrocatalyst for alcohol oxidation in alkaline media, Electrochim. Acta 206 (2016) 388-399.

[40] J. Lee, J. Yang, S.G. Kwon, T. Hyeon, Nonclassical nucleation and growth of inorganic nanoparticles, Nat. Rev. Mater. 1 (2016) 16034.

[41] P. Li, J. Liu, N. Nag, P.A. Crozier, Dynamic nucleation and growth of Ni nanoparticles on high-surface area titania, Sur. Sci. 600 (2006) 693-702.

[42] J. Ni, K. Noh, C.J. Frandsen, S.D. Kong, G. He, T.T. Tang, S. Jin, Preparation of near micrometer-sized $\mathrm{TiO}_{2}$ nanotube arrays by high voltage anodization, Mater. Sci. Eng.C 33 (2013) 259-264.

[43] X.H. Gao, Z.M. Guo, Q.F. Geng, P.J. Ma, A.Q. Wang, G. Liu, Microstructure, chromaticity and thermal stability of $\mathrm{SS} / \mathrm{TiC}-\mathrm{WC} / \mathrm{Al}_{2} \mathrm{O}_{3}$ spectrally selective solar absorbers, Sol. Energy Mater. Sol. Cells 164 (2017) 63-69.

[44] D. Venieri, I. Gounaki, V. Binas, A. Zachopoulos, G. Kiriakidis, D, Mantzavinos, Inactivation of $\mathrm{MS}_{2}$ coliphage in sewage by solar photocatalysis using metaldoped $\mathrm{TiO}_{2}$, Appl. Catal. B: Environ. 178 (2014) 54-64. 
[45] J. S. Sekhon, S. S. Verma, $\mathrm{Cu}, \mathrm{CuO}$, and $\mathrm{Cu}_{2} \mathrm{O}$ Nanoparticle Plasmons for Enhanced Scattering in Solar Cells, Renew. Energy and the Environ. OSA Technical Digest (CD) (2011) paper JWE22.

[46] Y.C. Nah, I. Paramasivam, P. Schmuki, Doped $\mathrm{TiO}_{2}$ and $\mathrm{TiO}_{2}$ nanotubes: synthesis and applications, Chem. Phys. Chem. 11 (2010) 2698-2713.

[47] S.C.S. Lai, R.A. Lazenby, P.M. Kirkman, P.R. Unwin, Nucleation, aggregative growth and detachment of metal nanoparticles during electrodeposition at electrode surfaces, Chem. Sci. 6 (2015) 1126-1138.

[48] A.K. Guo, Y. Fu, G. Wang, X.B. Wang, Diameter effect of gold nanoparticles on photothermal conversion for solar steam generation, RSC Adv. 7 (2017) 48154824.

[49] H.J. Chen, X.S. Kou, Z. Yang, W.H. Ni, J. F. Wang, Shape- and Size-Dependent Refractive Index Sensitivity of Gold Nanoparticles, Langmuir 24 (2008) 52335237.

[50] V.N. Pustovit, T.V. Shahbazyan, L.G. Grechko, Size-dependent effects in solutions of small metal nanoparticles, Eur. Phys. J. B 69 (2009) 369-374.

[51] X. Huang, I.H. Elsayed, W. Qian, Cancer cell imaging and photothermal therapy in the near-infrared region by using gold nanorods, J. Am. Che.Soc.128 (2006) 2115-2120.

[52] J.Y. Moon, M. Kemell, R. Punkkinen, H.P. Hedman, B. Park, A. Suominen, L. Heikkilä, H. Kim, A. Tuominen, Interference Colors of $\mathrm{TiO}_{2}$ Nanotube Arrays Grown by Anodic Oxidation, Adv. Mater. Res. 875-877 (2014) 370-374. 
[53] X.L. Zhao, G.W. Meng, Q.L. Xu, F.M. Han, Q. Huang, Color fine-tuning of CNTs@AAO composite thin films via isotropically etching porous AAO before CNT growth and color modification by water infusion, Adv. Mat. 22 (2010) 26372641.

[54] P.L. Stefchev, R.P. Kirilov, C.A. Girginov, AC-anodized and Ni-pigmented aluminum for selective solar absorption, Izvestiya Po Khimiya Bulgarska Akademiya Na Naukite 45(2013) 47-51.

[55] K. Jaiganesh, K. Duraiswamy. Experimental study of enhancing the performance of PV panel integrated with solar thermal system, Inter. J. Engin. \& Techno. $5(2013) 3419-3426$. 


\section{Figure captions}

Fig. 1. Synthesis procedure for the Ni-NPs@ $\mathrm{TiO}_{2}-\mathrm{NTA}$ : (a) the original Ti sheet, (b) a$\mathrm{TiO}_{2}$-NTA fabricated by a two-step anodizing, (c) the $\mathrm{Cu}\left(\mathrm{NO}_{3}\right)_{2}$ solution soaked and annealed $\mathrm{TiO}_{2}-\mathrm{NTA}$, (d) the electrochemically deposited Ni-NPs on $\mathrm{TiO}_{2}-\mathrm{NTA}$, (e) the enlarged part of (d), showing the photothermal conversion mechanisms.

Fig.2. Optical photographs: (a) Ti sheet, (b) Ti sheet after removing the first-anodized film, (c) Annealed $\mathrm{TiO}_{2}-\mathrm{NTA}$, and (d) Ni-NPs@TiO 2 -NTA. SEM images: (e) The prepatterned Ti sheet, (f) TiO2-NTA, (g) Ni-NPs@TiO 2 -NTA without soaking and (h) Ni$\mathrm{NPs@TiO} 2-\mathrm{NTA}$ with soaking in the $\mathrm{Cu}\left(\mathrm{NO}_{3}\right)_{2}$ solution. The inserts in (f), (g) and (h) are the corresponding enlarged top views.

Fig.3. (a) The average pore size of $\mathrm{TiO}_{2}$-NTA under different anodization voltages. (b) The average thickness of $\mathrm{TiO}_{2}$-NTA anodized at $60 \mathrm{~V}$ with various anodization times. SEM images of Ni-NPs@ $@ \mathrm{TiO}_{2}-\mathrm{NTA}$ with different deposition times: (c) 6.25 s, (d) 12.5 $\mathrm{s}$, (e) $25 \mathrm{~s}$, (f) $50 \mathrm{~s}$, (g) $75 \mathrm{~s}$, (h), $100 \mathrm{~s}$. The $\mathrm{TiO}_{2}-\mathrm{NTA}$ in (c) and (h) were anodized at $60 \mathrm{~V}$ for $50 \mathrm{~min}$.

Fig.4. (a) XRD patterns of Ni-NPs@ $@ \mathrm{TiO}_{2}-\mathrm{NTA}$ treated in air at different temperatures. (b) SEM image of Ni-NPs@ $\mathrm{TiO}_{2}-\mathrm{NTA}$ treated at $350^{\circ} \mathrm{C}$. (c) SEM image of Ni-

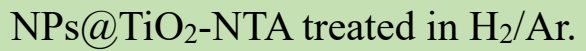

Fig.5. (a) Solar radiation spectrum and reflection spectra for different surfaces on Ti substrates. (b) Absorptance spectra and Kubelka-Munk plot (the insert) of $\mathrm{TiO}_{2}-\mathrm{NTA}$ with and without soaking. (c) Reflection spectra for Ni-NPs@ $\mathrm{TiO}_{2}-\mathrm{NTA}$ with and without soaking. (d) Reflection spectra for Ni-NPs@ $\mathrm{TiO}_{2}-\mathrm{NTA}$ with a thickness of 2 $\mu \mathrm{m}$ and different pore sizes. The data in bracket is the weighted absorptance of the samples.

Fig.6. (a) Reflection spectra for Ni-NPs@ $\mathrm{TiO}_{2}-\mathrm{NTA}$ with different thicknesses. (b) 
Reflection spectra for Ni-NPs@ $\mathrm{TiO}_{2}-\mathrm{NTA}$ with different Ni deposition times. (c) Reflection spectra for Ni-NPs@ $\mathrm{TiO}_{2}$-NTA with different calcination temperatures. (d) Reflection spectra for Ni-NPs@ $\mathrm{TiO}_{2}-\mathrm{NTA}$ with $\mathrm{H}_{2}$ reduction.

Fig.7. (a) Optical photograph of the water heating device. (b) The water heating under illumination and the recorded water temperature. (c) Heating curves of Ni-NPs@ $@ \mathrm{TiO}_{2}-$ NTA with different thicknesses. (d) Heating curve of Ni-NPs@TiO 2 -NTA with different deposition times. (e) The ATE of Ni-NPs@TiO $2-\mathrm{NTA}$ in (c), the thickness of NiNPs@TiO 2 -NTA on pure Ti sheet is regarded as 0. (f) The ATE of Ni-NPs@TiO2-NTA in (d). 


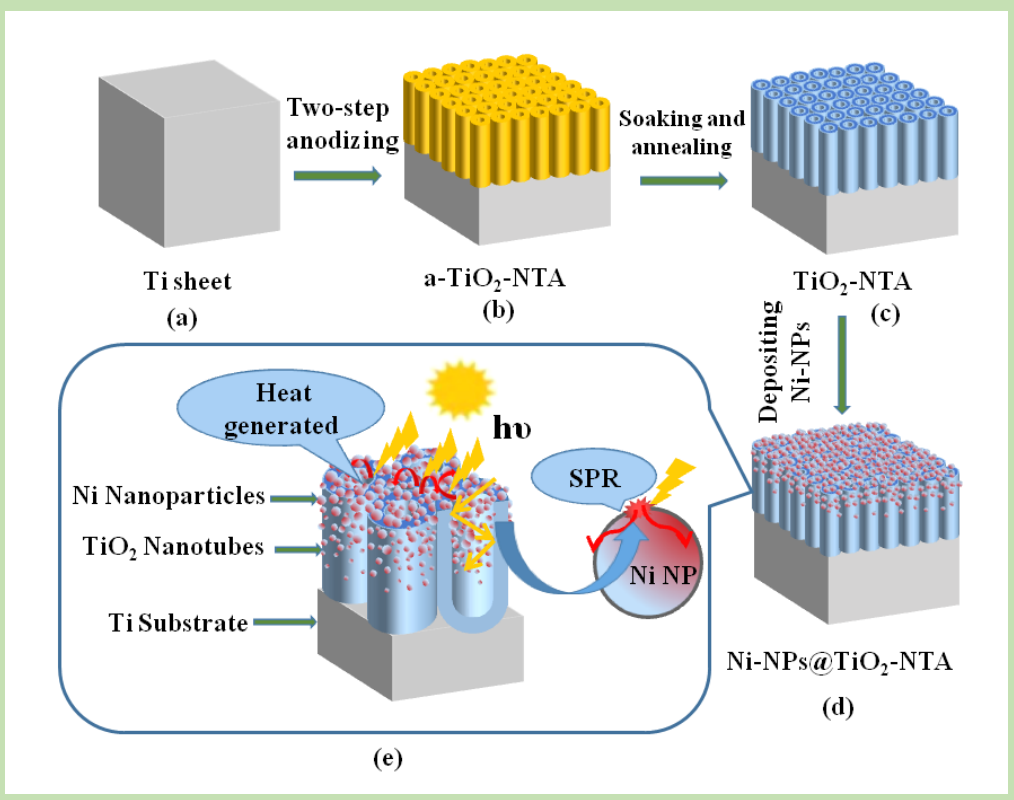

Fig.1. 

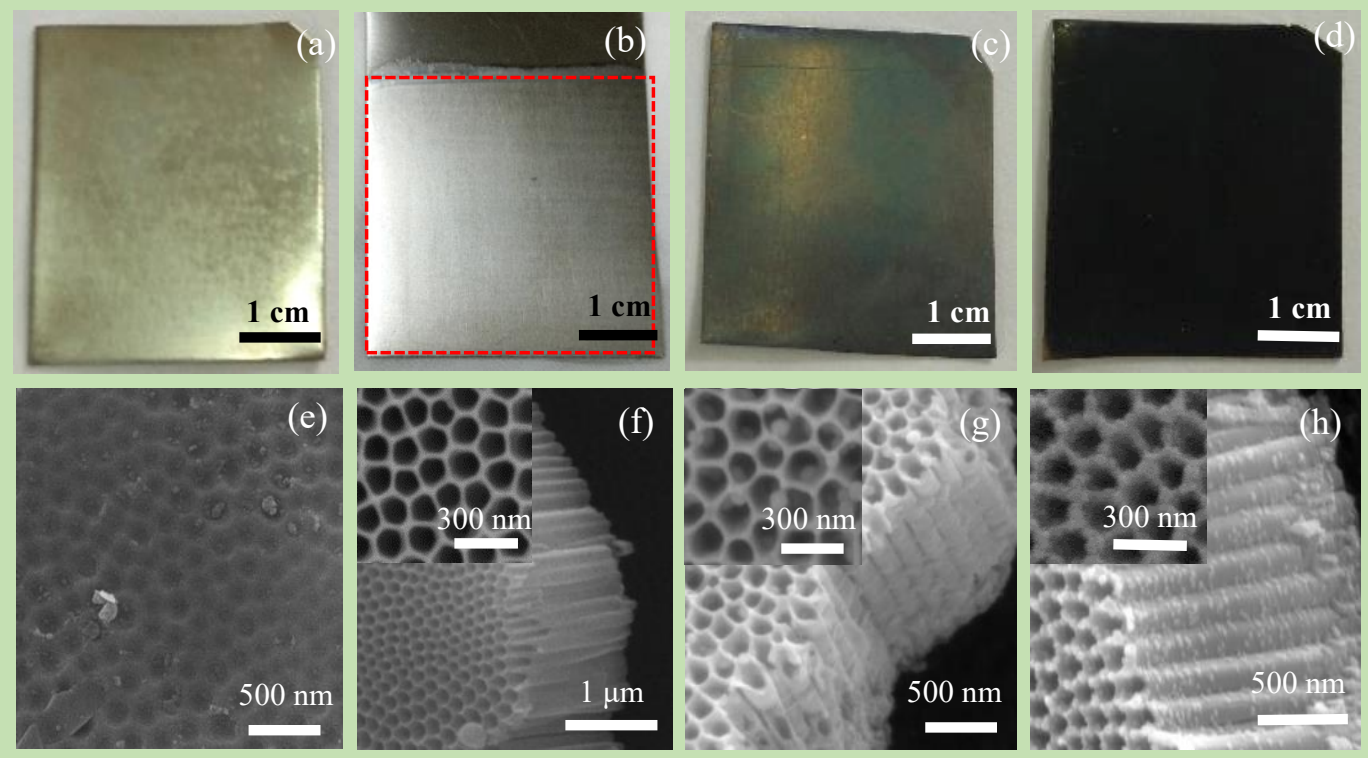

Fig.2. 

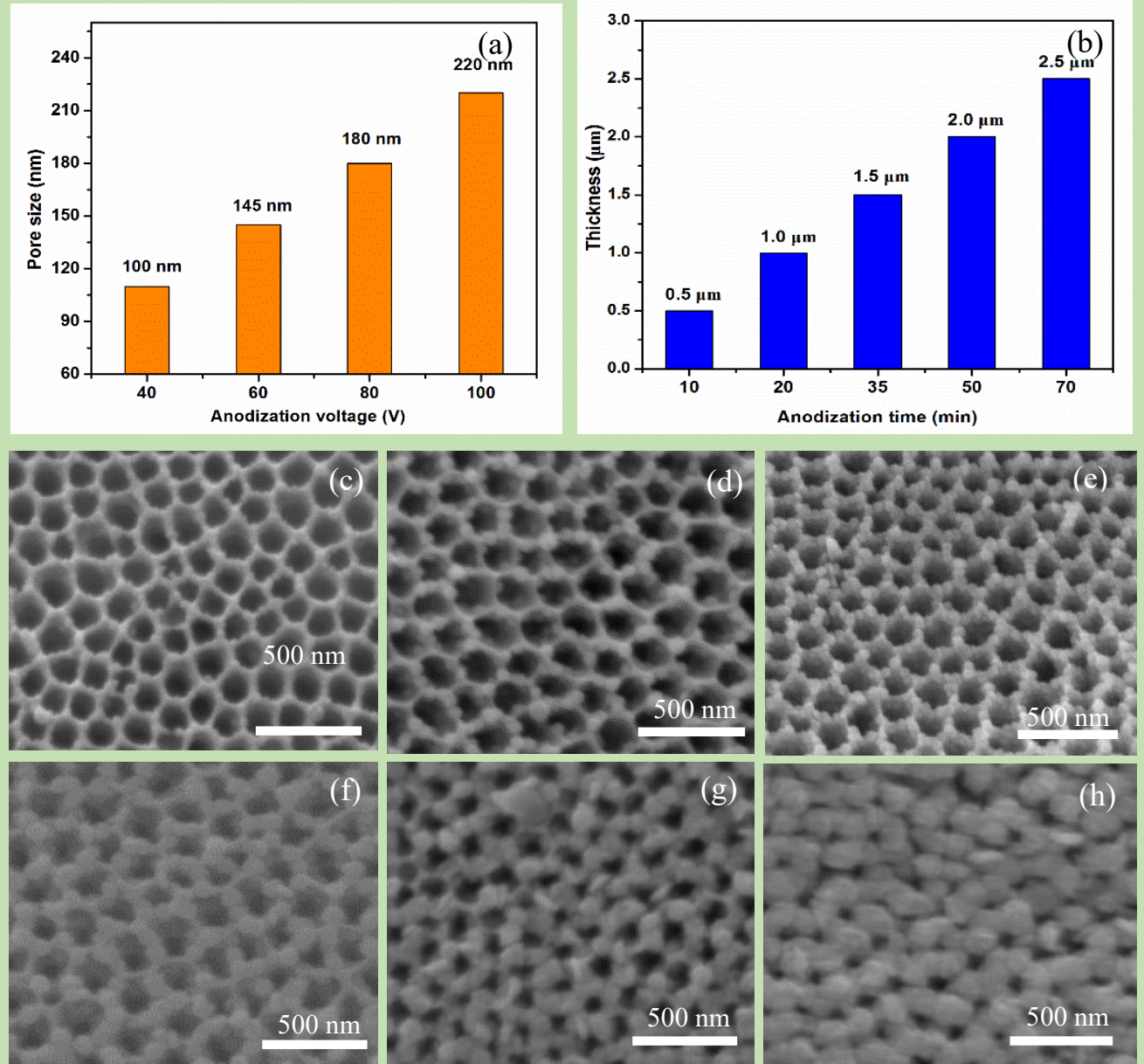

Fig.3. 

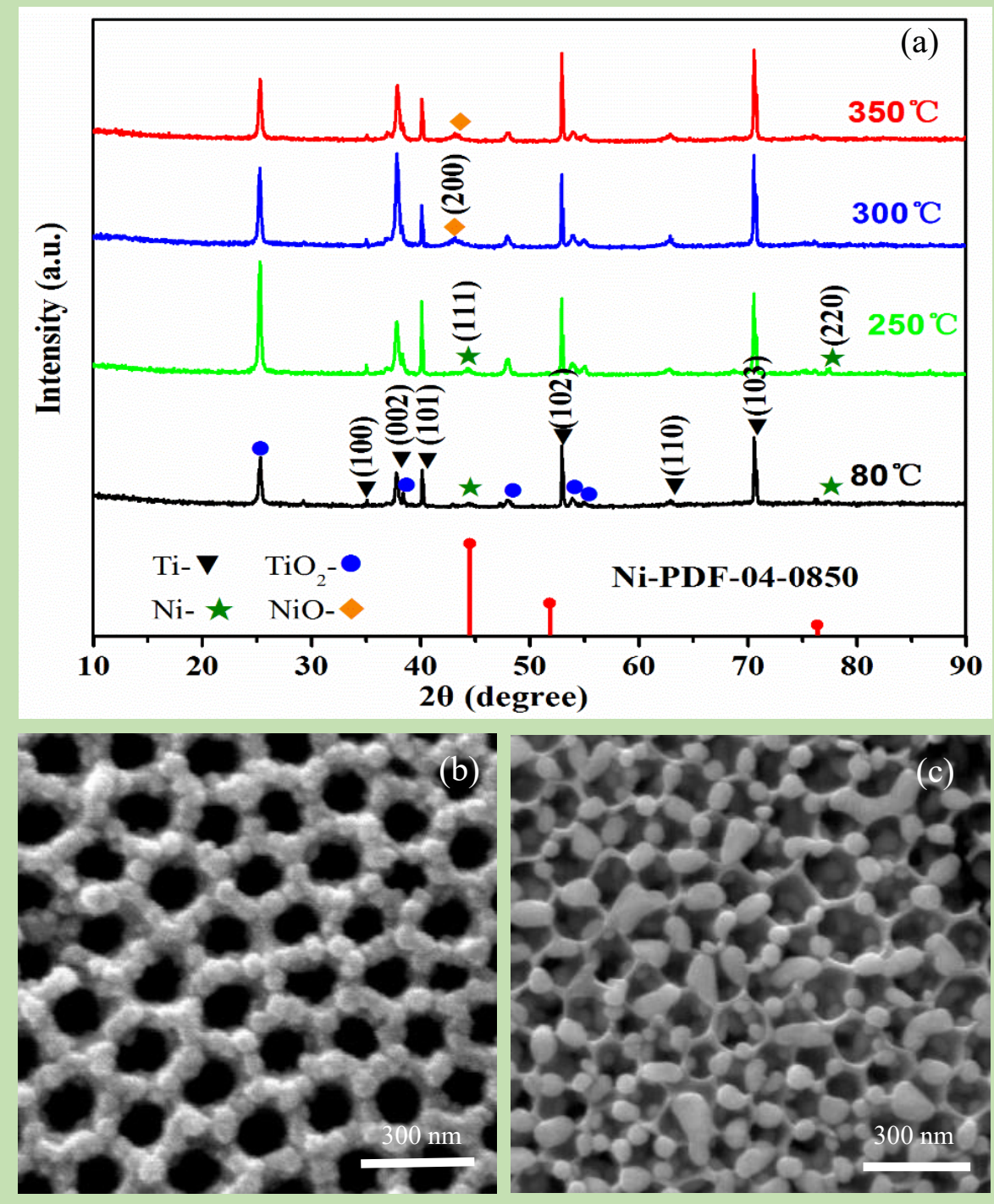

Fig.4. 

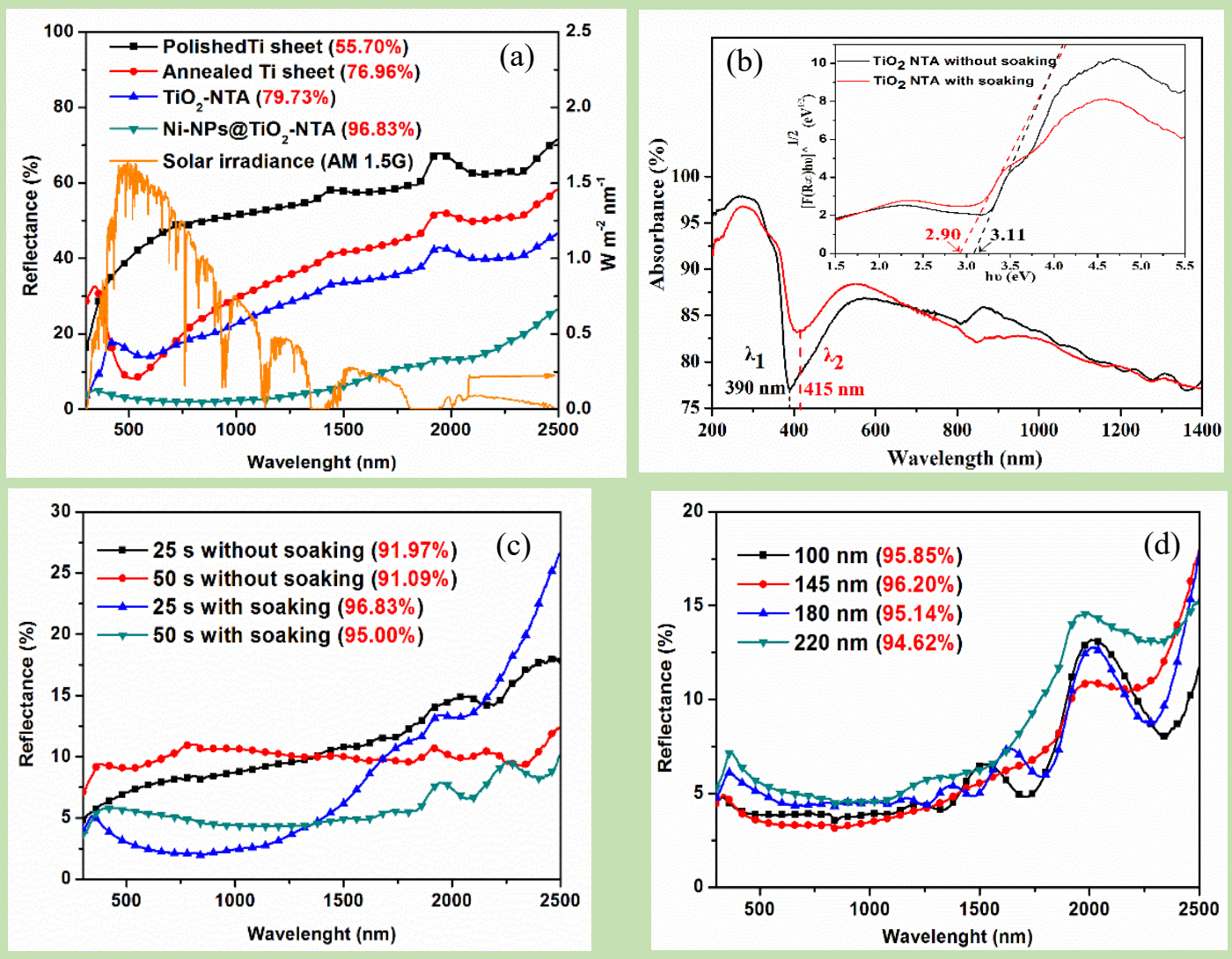

Fig.5. 

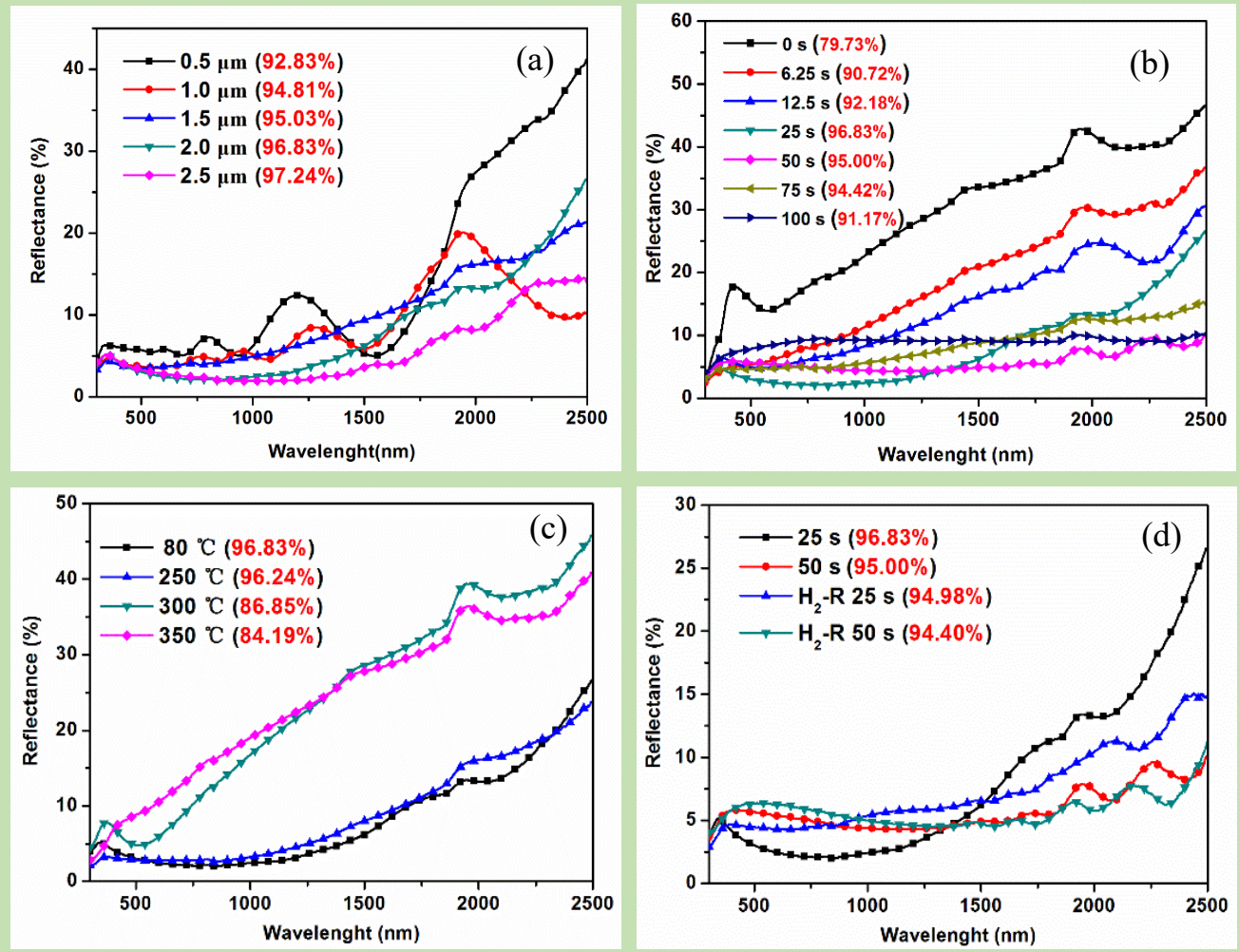

Fig.6. 

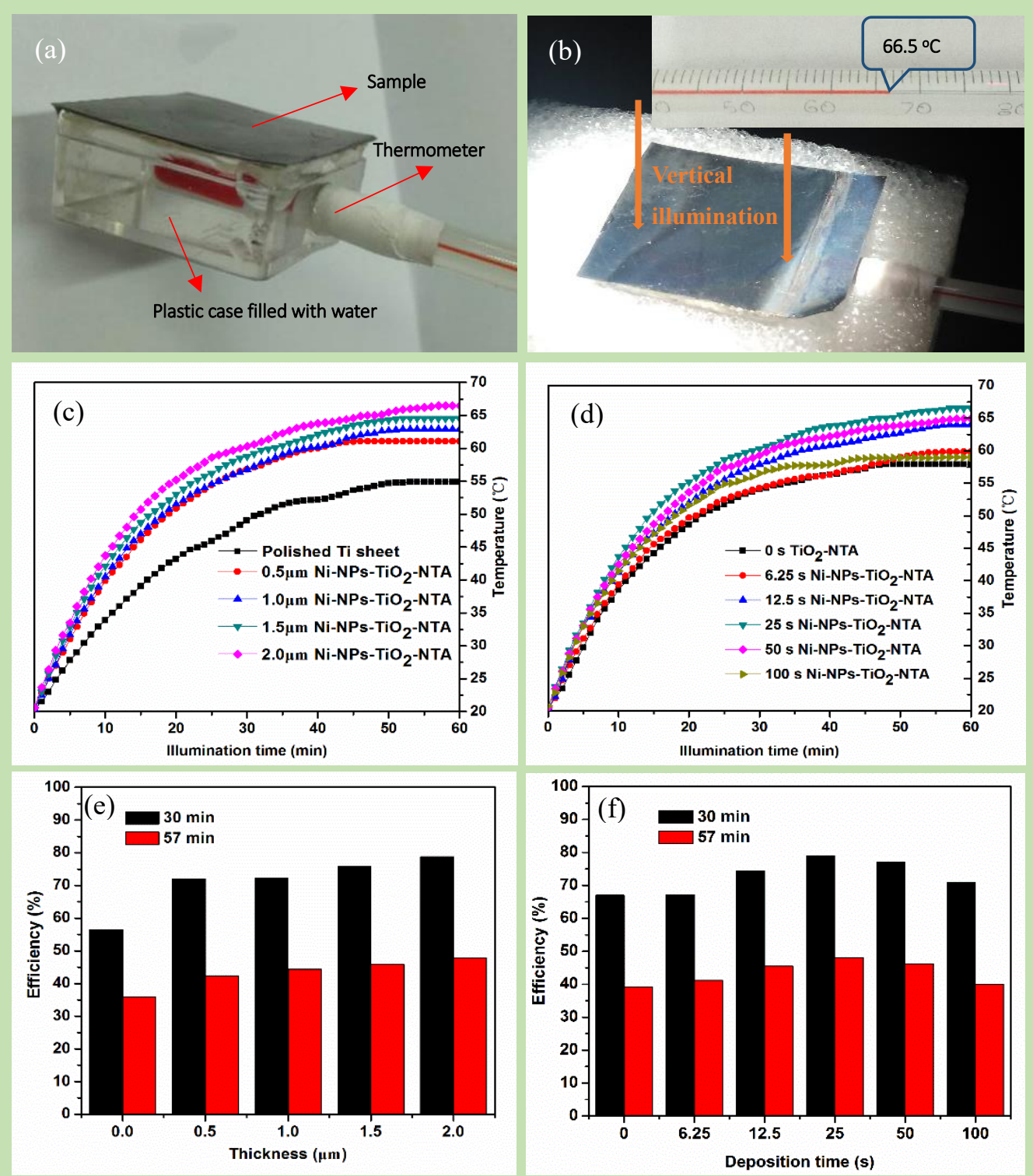

Fig.7. 


\section{Graphical abstract}

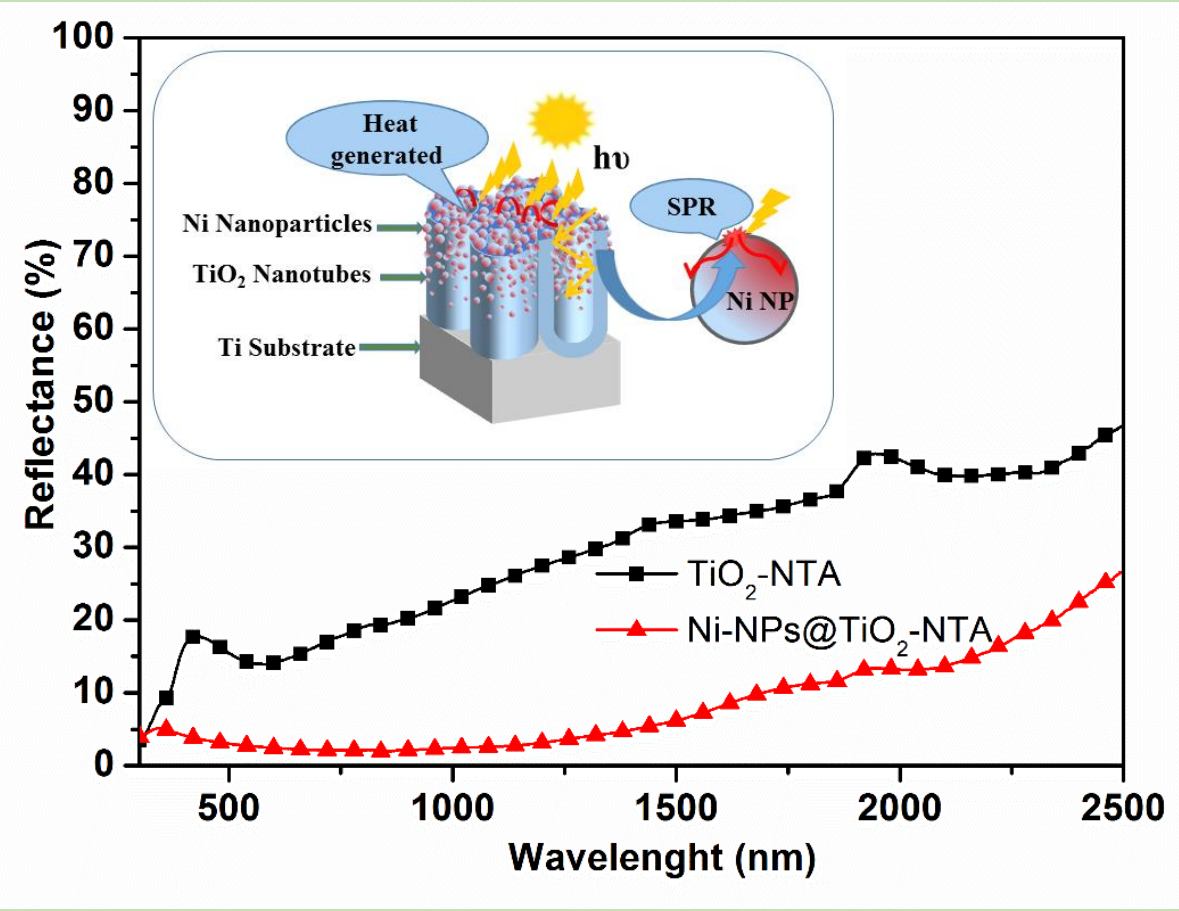




\section{Highlights}

- Ni nanoparticles have been highly-dispersed on $\mathrm{TiO}_{2}$ nanotube array.

- The size of $\mathrm{Ni}$ is significantly reduced after the pretreatment of $\mathrm{TiO}_{2}$.

- The properties of $\mathrm{Ni@TiO} 2$ can be well controlled.

- The composite exhibits high absorption and photothermal conversion efficiency. 